\title{
Comment
}

\section{Health Services Development Resource Assumptions and Planning Guidelines 1990/1991*}

\author{
M. M. Tannahill, Consultant Psychiatrist, North Wales Hospital, Denbigh, \\ Clwyd LL16 5SS.
}

In August 1989 the NHS Management Executive of the Department of Health issued Health Authorities with Circular $\mathrm{HC}(89) 24$ which lays down planning guidelines and rèsource assumptions for 1990/91. In five terse pages, the document sets the scene for the Government's priority health issues over the next two years. Several of these issues are of interest and importance to psychiatrists, as they are concerned with the implementation of the White Paper Caring for People: Community Care in the Next Decade and Beyond. Health Authorities are asked to "identify the health care needs of their populations" and to set targets, based on reports of their Directors of Public Health, to improve the overall health of their population.

Unfortunately, Departments of Community Medicine are undermanned nationally and their Public Health Directors are seldom knowledgeable about the epidemiology of mental illness. The College has recently set up a study group to prepare the epidemiological information which is so badly needed and this will be made available to District and Regional Medical Officers and managers. Armed with statistical knowledge, Health Authorities are instructed to ensure the availability of an appropriate range of services for:

(a) elderly and physically disabled

(b) children and adolescents with serious emotional and psychological difficulties

(c) mentally ill and mentally handicapped people.

These services, as envisaged in the White Paper, will normally be non-institutional. Health Authorities are, however, directed to build up their community services before moving patients from institutional care.

The White Paper itself makes it clear that joint planning between health, social services, voluntary agencies and the private sector will be required to ensure adequate community care for these vulnerable groups. Funding is to come from existing, 'ringfenced', social security monies, as well as from some new grants specifically for the social care of the men*Copies available from DHSS Store, Health Publications Unit, No 2 site, Manchester Road, Heywood OL10 2PZ, quoting $\mathrm{HC}(89) 24$.

tally ill. However, it is not as yet apparent how Health Authorities will be able to fund the new health facilities which will be required. Large capital sums are necessary to build DGH units, hospital hostels, long-stay psychiatric units for the severely mentally ill, and day hospital facilities, and these need to be up and running long before the assets of the mental hospital sites can be tapped.

HC(89)24 expects Health Authorities to proceed with these major schemes on an assumption of $1.5 \%$ overall increase in funding, along with projected additional profit from cost-improvement programmes and income generation. It is doubtful if any Health Authority will be able to realise sufficient cash from such schemes to make a significant contribution. Recently (December 1989) a loans scheme has been announced whereby Health Authorities may borrow short-term against anticipated long-term profitable assets. Health Authorities are directed to pay attention to quality in the services they provide. As a start, and with relevance to psychiatry, each District must draw up "care programmes" which provide coordinated care for people with chronic mental illness, and "action plans" to meet the health care needs of those with mental handicaps. Again the Royal College of Psychiatrists has been taking a lead in these matters, having already drawn up 'Guidelines for Good Medical Practice in Discharge and After-Care Procedures for Patients Discharged from In-patient Psychiatric Treatment', and also with its preliminary Audit Report.

Finally Health Authorities are urged to pursue the implementation of Achieving a Balance and to seek improved patient care by employing both more consultants and by reducing onerous junior staff rotas. For non-psychiatrists this medical manpower issue has been addressed by the closing of small hospitals and aggregating their functions on large DGH sites. The White Paper Care in the Community, on the other hand, with its philosophy of providing care in small units close to where patients live, may be more expensive of medical manpower. An appropriate task for the College Manpower Committee in the ' 90 s will be to study how, in medical staffing terms, such care can be most effectively provided. 